\title{
Doing our best
}

\author{
Elizabeth Kay
}

As we have lived through the hideous ordeal called the COVID-19 pandemic, it has occurred to me that science and global cooperation have never been so terrifyingly urgent and so utterly important. Both the urgency of producing universally relevant research, and the importance of putting it into practice, are principles upon which I have always based the ethos of EvidenceBased Dentistry.

Unfortunately, also during this crisis, I have witnessed (albeit viewed remotely via email or online), in the various arenas in which I work and communicate, individuals and organisations competing to be the 'owners' of the scientific truths, and a will to be seen as THE most knowledgeable source of information. Suddenly, everywhere, there seem to be 'experts' in some aspect of communicable disease, microbiology, immunology, and everywhere people seem to be popping up who seem to believe that they know best about the disease, and that they have the keys to unlocking the current dilemmas and challenges facing dentistry. These people, often part of large and prestigious organisations or institutions, claim that they know the 'correct' 'evidence-based' way forward, and they seem to feel able to tell dentistry what actions it should be taking. They are keen, understandably, to provide leadership to a profession which finds itself in a desperately difficult situation, clinically, financially, and ethically. This will to advise, while entirely understandable, is also dangerous.

COVID-19 is a NEW virus. Its behaviour is unknown, its lethality unexpected, and its immunological mechanisms poorly understood. The important fact is...it is NEW, novel, recent and unfamiliar. And the science to unravel its complexities, and thereby effectively guide our actions, will take time. Top scientists in every country are working at full pace, and, very importantly, in very close collaboration with each other, in order to find answers. This work is, naturally, focussed first on the immediate need to save lives where we can, and on protecting those at most risk. And although WE believe dentistry to be of prime importance, in this instance, our needs have had to wait a while. As the facts are becoming established for the 'front line', and for other specialities and professional groups, we now have to translate them, and study matters further in the context of our own profession, and our patients' particular needs.

I believe there is only space for cooperation, not competition. The requirement, as I write this is, more than anything, mutual support. Most importantly, we need to recognise that, as yet, we know very little for certain about the role of COVID-19 in, and its potential effects on, dentistry. However, what is certain is that we will, in time, understand more about the best way forward. New knowledge and new ways of working, and perhaps behaving, will emerge from this global crisis.

In this spirit of increased global understanding and cooperation, I have asked a number of colleagues in different parts of the world to write something about their experience and perspective on the pandemic. Their contributions are in this issue, and I thank them for these insights.

It seemed somewhat illogical, given the current crisis and its massive effect on our professional lives, to publish an issue of Evidence-Based Dentistry reviewing research about normal practice in dentistry, since $95 \%$ of that is no longer occurring.
It seemed to me that what you might want would be for us to comment on the emerging evidence with direct relevance to dentistry. So that is what we have done. I want to extend huge thanks to Helen Nield, Head of Library and Knowledge Services at the BDA who has provided an up-to-theminute supply of publications relating to COVID and dentistry, to both me, and to the BDA Health and Science Committee. I also would like to thank, from the bottom of my heart, the commentators who have reviewed this evidence, sometimes at very short notice, and lastly I apologise to the commentators whose contributions are being pushed back into later editions in order to accommodate this COVID special issue. I hope you agree that it is the right thing to do.

It has to be said that none of the evidence available is very strong or of high quality, but, since evidence-based practice is about combining the best available evidence, with clinical judgement and patient preferences, I just hope that the content of this issue may be useful as we start to prepare for our journey towards recovery.

What I will promise, for the future, is that we will, as the evidence emerges, do our very best to distil and disseminate it, and we will try our best to determine the practical actions we should take based on the best and latest evidence. But until better evidence is carefully collected, checked, analysed and specifically made relevant to the context of dentistry, we can only wait. For now, we must do our best to stay safe so that we emerge stronger, and ready to act to help our patients in the best, evidencebased ways possible.

Evidence-Based Dentistry (2020) 21, 38. https://doi.org/ 10.1038/s41432-020-0107-5 